\title{
Cultural Ways of Constructing Knowledge: The Role of Identities in Online Group Discussions
}

\begin{abstract}
Learning scientists and the CSCL community have argued that knowledge construction is a process of collective thinking; a process that is simultaneously personal and social that requires group cognition. However, while CSCL researchers have investigated situated knowledge in the process of collective thinking, little work has been done to fully understand how different identification categories play a role in sense-making and knowledge construction. This research, therefore, explores in detail how individuals operationalize identification categories when they engage in group discussions in online learning environments. Results demonstrate that individuals do not experience online learning through only one aspect of their identity. Rather, learning experiences evoke different elements of their identities that are used continuously and simultaneously when they collaborate with each other in the phases of knowledge construction.
\end{abstract}

\section{Introduction}

Learning scientists have long argued that learning is tied to context and that learning is simultaneously a personal and social process: a process of identifying oneself in relation to others in cultural worlds (Cole, 1996; Holland, Lachicotte Jr, Skinner, \& Cain, 1998). It is through this mediation between the self and others between the personal and social - that identities become central for collaborative learning. As I discuss later, I understand identities as context-bound enactments, where the context enables and constrains sets of social practices(Holland et al., 1998).

There is a growing body of research in the CSCL community examining the relationship between identities and knowledge in online environments (e.g., Arvaja, 2012; Ke, Chávez, Causarano, \& Causarano, 2011; Ligorio, Loperfido, \& Sansone, 2013; Suthers, 2006). For example, the work cited in Ke et al. (2011) correlates the aggregates of identity manifestations with individual cognition in seven online courses. That work is valuable for indicating an overall positive relationship between identities and knowledge building, but it does not explain how identification is situated in and mediated by the discursive activity among individuals. Similarly, the work described in Ligorio et al. (2013) correlates the frequency of dialogic indicators (using the Bakhtinian concepts of polyphony and chronotope) with different identity manifestations. Ligorio et al.'s work illustrates that identification takes peculiar paths and twists and that individuals have unique identity trajectories. What these twists and turns of identification mean for knowledge, sense-making, and group work, however, remains unanswered. Arvaja's (2012) work is a qualitative contribution of how identification helps individuals apply situated meanings to group work. That research considers group work as a process of collective thinking and uses case studies to probe how individuals use their personal background to make sense of their learning experiences. Arvaja's work is an important step as it illustrates the ways that individuals manifest their identification in and by dialogue; yet, it does not explicate how identities relate to knowledge construction.

The present work builds on the aforementioned studies, and it aims to address one important question that remains unanswered: what is the role of identification in knowledge construction when individuals engage in group work in online learning environments? If identities are central for collaborative learning (Holland et al., 1998; Wenger, 1998), and if collaborative learning is all about sharing, cultivating, and constructing knowledge (Ke et al., 2011; Stahl \& Hesse, 2009), then it is prudent to explore the relationship between identification and knowledge. Within the framework of sociocultural learning theories, therefore, I exemplify how individuals utilize different identifications to make situated meanings, and how these meanings relate to knowledge construction in online group discussion. To be more specific, I deconstruct how individuals identify themselves in online discussions and investigate the ways by which group discussion enables meaning-making, knowledge construction, and shared understanding. I put the relationship between identification and knowledge construction at the centre of my analysis because if we disregard the role that different identity manifestations play in group work, we "not only fail to see how knowledge is situated and distributed in the discursive activity among different participants, but also fail to recognize how knowledge is mediated by the material and sociocultural aspects of situations" (Arvaja, 2012, p. 86).

\section{Concepts, Theories, and Approaches}

Knowledge construction is a situated process that includes social and cognitive interactions ranging from simply sharing information, to negotiating meanings, to summarising and synthesizing new knowledge (van Aalst, 2009). It is not merely an exchange of information but requires coherence and convergence among participants of a learning community. The pedagogical benefit of learning community: 
is not just that two minds are quantitatively better than one or that the whole has a Gestalt that exceeds the sum of its parts. The synergy of collaboration arises from the tension of different perspectives and interpretations. ... A meaning is constructed at the unit of the group as utterances from different participants build on each other and achieve an evolving meaning. (Stahl, 2006, p. 299)

Because knowledge is constructed precisely through negotiating personal and shared understandings, we should explore the role of subject positions on knowledge construction.

The concept of identification can explain the link between personal perspectives and interpretations on the one hand and shared meanings and collective knowledge on the other. Indeed, sociocultural learning theories have long deemed learning as an aspect of practice-based identity (Lave \& Wenger, 1991), where knowledge is distributed through and mediated by the participants of a community (Gutiérrez \& Rogoff, 2003; Nasir, Rosebery, Warren, \& Lee, 2005). Such an understanding is particularly important as it "reconceptualizes learning from an in-the-head phenomenon to a matter of engagement, participation, and membership in a community" (Nasir \& Cooks, 2009, p. 42). Here, I adhere to sociocultural perspectives and argue that by exploring the role of identification in knowledge construction, we can enhance what we know about supporting and sustaining group work in online learning environments. Employing the concept of identification invites a discussion about the meaning of the concept, the way it differs from identity, and its appropriateness as a theoretical framework for exploring knowledge construction.

\section{Identification and Its Relation to Knowledge Construction}

The concept of identity has been at the centre of many political, philosophical, economic, and academic debates. For example, politically, identity refers to how various social groups struggle for recognition within a society and how these groups are affected by various institutional practices (Gramsci, 2000). Philosophically, identity is associated with the question of whether people are uniquely human or whether they share a degree of sameness with others in a particular time and space (Heidegger, 1962). Academically, it has been deemed vital by many disciplines; yet, identity means different things to different scholars from different disciplines. Notions of identity are as diverse as the literatures in which they are used. Fields as diverse as psychology, sociology, physical sciences, humanities, and philosophy offer discipline-specific conceptualizations and definitions of identity. Thus, the concept of identity has been overused in academia and its meaning is ambiguous: it may mean too much, too little, or nothing at all (Brubaker \& Cooper, 2000).

Untangling this ambiguity is challenging. The conundrum becomes evident through a look at the word's etymology. According to the Oxford English Dictionary, the term was appropriated from a Latin word "idem", meaning the sameness or being identical. Yet, the concept of identity implies both similarity and difference and much of the debate regarding identity stems from the tensions between these two aspects (Buckingham, 2008):

On the one hand, identity is something unique to each of us that we assume is more or less consistent (and hence the same) over time. ... Yet on the other hand, identity also implies a relationship with a broader collective or social group of some kind. ... On one level, I am the product of my unique personal biography. Yet who I am (or who I think I am) varies according to who I am with, the social situations in which I find myself, and the motivations I may have at the time, although I am by no means entirely free to choose how I am defined. (p.1) identity.

This dilemma marks the fundamental difference between essentialist and relativist approaches to

Essentialist perspectives typically contend that individuals have an authentic or essential self, assuming that individuals have relatively consistent and stable identities. Based on Erikson's stages of psychosocial development (Erikson, 1968), these perspectives conceptualize identity as resolving role-confusion and argue that identity is internally coherent. Individuals consider potential life choices and commit to or invest in particular decisions based on the stage of their psychological development. This understanding, however, is very normative and suggests that identity is a single state of integrity that one achieves over time and development. Accepting identity as a predefined state of self disregards the contingent nature of identity and falls short in providing sufficient means to understand the complex human experience (Hall, 1996).

This idealist and normative framework can be found in much online learning research, where individual members of a group are assimilated into a singular identity. For instance, when research argues that "online courses benefit a wide variety of students, but perhaps none more dramatically than nontraditional female students" (Sullivan, 2001, p. 817), it not only suggests that there are sufficient commonalities among 
"non traditional female students" to allow this analysis to be made but also implies that there is a predefined way to be a female in online learning environments. The underlying theoretical assumption is that gender categories are fixed, and that they themselves are meaningful for explaining certain online learning experiences. Similarly, when researchers suggest that African American students have a significantly weaker sense of community compared to their White American peers in an online course (Rovai \& Ponton, 2005), it implies that the category of race itself is sufficiently meaningful to inform the understanding of different societal factors that might contribute to a sense of belonging. As it would be a mistake to suggest that White Americans are more friendly or open for communication than African Americans, it seems clear that race alone cannot explain this apparent finding. Similar online learning studies making such claims include but are not limited to: a crosscultural study of social interaction behaviours among Korean, American, and Finnish students (Kim \& Bonk, 2006); a quantitative comparison of online learning experience between US and non-US students (Bently \& Tinney, 2003); an examination of online success contingent on individuals' cultural background (Mills, Eyre, \& Harvey, 2005); and an investigation of pedagogical differences between Chinese and Western students (Ku, Pan, Tsai, Tao, \& Cornell, 2004). To be clear, my concern here is not that these categories may in some cases may have explanatory power, but that we cannot assume that individuals will choose to enact these particular identities in particular situations and at particular times.

Relativist perspectives suggest that identity is something people enact or perform as opposed to something people have. Individuals assume and enact identities based on available material and symbolic resources, and one's identity depends on the process of classifying, labelling, or linking individuals in relation to one another. Identities are situated in and bounded by sociocultural dynamics that exist in any given community (Jenkins, 2008) and they are enacted "on the back of a recognition of some common origin or shared characteristics with another person or group" (Hall, 1996, p. 2). Precisely because identities are enacted or performed, many scholars have argued that identification can be useful in understanding the personal and social aspects of symbolic boundaries (Brubaker \& Cooper, 2000). Thus, identification can explain:

how people categorize or label themselves and others, how they identify as members of particular groups; how a sense of group belonging or community is developed and maintained, and how groups discriminate against outsiders; how the boundaries between groups operate, and how groups relate to each other (Buckingham, 2008, pp. 5-6)

Operating at both social and individual levels, identification is an on-going interplay between social context and personal enactments.

By and large, sociocultural learning theories typify relativist perspectives and this influence is evident in much learning sciences research. For example, research has argued that identities are enactments within figured worlds, where individuals' practices are constrained or enabled by a set of social norms in these worlds (Holland et al., 1998; Lave \& Wenger, 1991; Nasir \& Cooks, 2009; Nasir et al., 2005). If identities are particular enactments in a given context, how, then, can we understand the role identifications play in knowledge construction?

\section{Knowledge Construction and Its Relation to Identification}

Despite the never-ending debate on its meaning, knowledge can be defined as theoretical or practical understanding of facts, information, and skills that are implicitly or explicitly acquired through perception, experience or education. Since "views of education and the development of knowledge depend on assumptions about the nature of knowledge itself" (Atwood, Turnbull, \& Carpendale, 2010, p. 358), I shall briefly demonstrate how the paradigm shifts of knowledge are reminiscent in current pedagogical theories and practices including those of CSCL.

Philosophically, the Western school of thought since the time of Plato has focused on the a priori or $a$ posteriori nature of knowledge and its relation to the notions of truth, belief, experience, and justification. Descartes scrutinised the role of the objective world and subjective consciousness in the process of knowing and thus epistemologically separated the subject and the object of knowledge (Kuhn, 1970). This separation is known as the "Cartesian Divide" and it can be found in many disciplines and research domains, including behaviourism, which laid the foundations of educational thought in its early days. The reunion of the subject and the object of knowledge came with the paradigm shift of post-modernism, where knowledge is not only bounded by a time/space scale but also framed as a meta-narrative that implicitly defines our ways of being (Lyotard, 1984). These different understandings of knowledge led to different conceptualisations of knowing: scepticism that knowledge is impossible, dogmatism - that knowledge is possible and absolute, and relativism - that knowledge is possible but has no objective significance.

Pedagogically, scholars have focused on the relationship between knowledge and learning, and have 
suggested numerous pedagogical approaches for acquiring, utilising, cultivating, and sharing knowledge. Early educational theories equated learning with acquiring knowledge (the Cartesian Divide that knowledge is separate from students, and that it can be learned through stimuli-response instructions), and "focus[ed] on the mind of the individual student as the unit of analysis when looking for instructional outcomes, learning, meaning-making or cognition" (Stahl, 2005, p. 79). In reaction to this behaviourist stimuli-response approach, learning scientists have created more nuanced accounts to conceptualise and address knowledge, collaboration, and learning as relational and situated phenomena (Bereiter, 2002; Koschmann, 1996; Pea, 1993; Salomon, 1993). The paradigm of CSCL is built on these relativist accounts and accepts knowledge as "socially constructed through collaborative efforts toward shared objectives or by dialogues and challenges brought about by differences in persons' perspective" (Pea, 1993, p. 48). As knowledge is socially constructed, and meaningmaking or knowledge building cannot be attributed to individual group members (Stahl, 2005), knowledge construction is not so much about the mind of an individual student as it is about group work. Indeed, group work and the context in which group work occurs are at the centre of CSCL work concerning knowledge construction.

Knowledge construction is defined as a set of social and cognitive engagements that advances the state of knowledge within a community through discourse (Scardamalia \& Bereiter, 1994). In other words, knowledge construction is group work, whereby participants share, utilise, cultivate, negotiate, and critique knowledge (Stahl \& Hesse, 2009) while generating "qualitative changes in the complexity of [their] thinking about and conceptualization of context-specific subject matter" (Moore, 2002 as cited in van Aalst, 2009, p. 261). Because "the thinking of each individual is inevitably influenced by the thinking of the other members taking part in discussion" (Gunawardena, Lowe, \& Anderson, 1997, p. 409), construction of knowledge is interdependent on individuals' knowledge. At the heart of this interdependency is the concept called intersubjective meaning making; a process of collaborative meaning making in its context (Koschmann, 1996). Yet, context cannot be predefined nor can it be understood merely as the physical or virtual environment in which collaboration occurs. It is instead a perceptual space that is dialogically constructed, where material realities of the social, historical, economical, and political discourses intersect (Bakhtin, 1986; Cole, 1996). As I have argued elsewhere, context, particularly the online context is something participants co-create as they socialise themselves with others in the activity (Author, 2012a). Thus, in order to capture the nature of knowledge construction, we need to understand the situational dynamics of group work and address "collaborative knowledge construction as a temporally evolving context-bound phenomenon" (Arvaja, Salovaara, Häkkinen, \& Järvelä, 2007, p. 449). It is only then that we can frame context as a dialogical construction and study it as an ongoing manifestation of sociocultural dynamics in group work.

The appreciation of context is core to learning sciences research since its early days (see, for example, Jordan \& Henderson, 1995; Pea, 1993), and the research exploring the dialogical construction of context continues to grow. For example, the research described in Atwood et al.'s (2010) study explores the dialogical construction of inter-subjective meaning through the co-construction of discourse - defined as exploratory, cumulative, and disputational talk. It posits that when students engage in disputational talk, particularly cooperative forms of talk, they can develop a mutual understanding for each other. Despite the rather openended definition of cooperative talk (i.e. offering points of view, asking questions, gently challenging), Atwood et al.'s study provides evidence that discourse is fundamental for co-constructing the context and that intersubjective meaning-making requires coherence and convergence among participants. Engle's (2006) work tackles the ways of constructing a discourse that can be coherent to its community of learners. It focuses on the ways in which promoting context as the intersection of personal interests, professional experience, and past knowledge can help students to draw from their own experiences when they make sense of the subject matter. According to that work, students' prior knowledge and experiences become means for constructing a situated context in which students build on others' knowledge to advance their own understanding. While knowledge construction is not the specific focus in Engle's work, it does demonstrate that students' sense of self creates the social fabric for inter-subjective meaning making. Similarly, the work described in Arvaja's (2012) study investigates how personal and shared resources - defined as semiotic, material, social, cognitive, and cultural resources - can create the social fabric: personal and shared resources function as inter-contextual and intertextual ties in joint activities. These ties provide opportunities for students to develop a "collective criticism" (p. 104), which guides and frames inter-subjective meaning making. Inter-contextual and inter-textual ties, then, indicate the temporal and intertwined nature of the context. Research in Tee and Karney's (2010) work further probes the intertwined nature of the context, asserting that individuals' learning becomes distinctive when they have an opportunity to read their classmates' real-life experiences. It suggests that academic content knowledge alone is not enough for knowledge construction; thus, the context should provide opportunities for students to draw from their prior knowledge and apply the concepts they learn to their profession.

Taken together, this research argues that knowledge is not an absolute end but rather an iterative 
process of negotiation and discussion: knowledge is distributed among individuals and it is bounded within, affected by, and developed from social interactions over time. Consequently, knowledge construction is about dialogical construction of context, in which knowledge can be utilised, shared, and cultivated. It is this temporal and situated nature of the context that makes identification particularly important for knowledge construction. Identification creates the social fabric of the context, and thus the social fabric of inter-subjective meaningmaking, by helping individuals situate knowledge in its context and create a link between personal mind and collective meaning. As I have argued elsewhere, articulating who they are and knowing who their peers are, individuals can have better opportunities to situate themselves in relation to others, as well as situate knowledge in its context (Author, 2012b).

\section{Identification And Knowledge Construction in the CSCL context}

Currently, the vast majority of online courses employ asynchronous threaded discussions for reflecting on and reacting to insights and perspectives. A thread is a "hierarchically organized collection of notes in which all notes but one (the note that started the thread) are written as 'replies' to earlier notes" (Hewitt, 2005, p. 568). Generally, a weekly discussion comprises multiple threads, though it is not uncommon for a weekly discussion to revolve around just a single thread. As the main social and cognitive tools for communicating knowledge and negotiating identifications, threads "on the one hand provide a means to improve conceptual artifacts together, and on the other hand, provide a permanent way of representing them, where the students recognize their own understanding in others' postings" (Arvaja, 2012, p. 105). This shared repertoire of insights and perspectives, then, becomes collective knowledge that helps individuals develop situated meanings in group discussions. Precisely because threads are developed while individuals negotiate a shared repertoire, their analysis can reveal much about the process of collaboration and knowledge construction. In a sense, a thread can be accepted as a micro-context in itself with its own unique sociocultural dynamics. Consequently, if we are to understand knowledge construction in online group work, we should address threads as a temporal construction of context.

I suggest that employing identification as a theoretical lens to analyse online discussions can provide means to understand how individuals perceive themselves in relation to others when they engage in group work. I follow sociocultural learning theories and argue that depending on the context, individuals choose to use different identifications through which they articulate their previous experiences while they make sense of new subject matter. Identification, in this sense, reflects sets of meanings derived from agreements or disagreements that occur in the process of group work.

For the purpose of data analysis, and for the rest of the discussion, I regard identification as means by which individuals articulate themselves in group work and as enactments that individuals perform when they engage with each other.

\section{Current Research}

This study explores the role of identification traits (i.e. gender, profession, group affinity, or ethnicity) in the process of knowledge construction through multiple case studies (Creswell, 2006). I regard a case study as a procedure of inquiry, an in-depth exploration of a certain event in a given context (Merriam, 2009). Therefore, I use three purposefully selected cases in order to illustrate three different ways in which identifications play a role in knowledge construction: the first case shows that different individuals can utilise different identifications, the second case shows that individuals can enact more than one identification in a single thread, and the third case shows that categories of identification (e.g. gender or ethnicity) can mean different things to different individuals. While each case presented here suggests an alternative conceptualisation to the aforementioned normative perspectives, taken together, these cases posit that the relationship of identification to knowledge is situated in its social context.

In order to illustrate the variety of identification traits individuals manifest, a research team (the author and his two colleagues) analysed the participants' profile pages (personal pages in which students create their online existence by introducing themselves with their own words and a picture or avatar) and created an online persona for each participant to materialise the salient identification traits. The research team paid considerable attention to choosing individuals who use a variety of identities and selected four individuals who maximize the exploration of the phenomenon (personas are explained in detail below). After the online personas were decided, threads with knowledge construction were identified using the model in Gunawardena et al. (1997) (explained in detail below). In order to capture knowledge construction, notes in threads were coded as to whether they were new ideas (Phase 1), modifications of existing ideas (Phase 2-4), or metacognitive statements (Phase 5), and knowledge building is said to be observed when those metacognitive statements advanced the collective knowledge. In particular, each of the three members of the research team independently analyzed all of the notes. Then, we came together and, for each note on which we disagreed, we discussed until consensus was reached. The research team then analysed the notes in these threads semantically (Fairclough, 2001) with three 
different lenses: (1) the use of identification, (2) the process of knowledge construction, and (3) the relationship between the two.

The use of identification is analysed simply with probing "who says what" (Fairclough, 2001) in language-in-use. The analysis of language-in-use reveals how identification traits are manifest in ways of saying, doing, and being:

If I say anything to you, you cannot really understand it fully if you do not know what I am trying to do and who I am trying to be by saying it. To understand anything fully, you need to know who is saying it and what the person saying it is trying to do. (Gee, 2011, p. 2)

Since the language-in-use is linked with the role that identification traits play in mediating experiences among individuals, "who says what" is critical for understanding the otherwise hidden intersections between identification, situated meaning-making, and knowledge construction in online learning environments.

The process of knowledge construction is analysed through an "interaction analysis model", as explained in Gunawardena et al. (1997). The interaction analysis model is grounded in sociocultural learning theories and it is specifically developed for analysing asynchronous threaded discussions as a process of negotiation (Wise \& Chiu, 2011). In particular, the model conceptualizes knowledge construction as a group discussion, whereby the process of social negotiations advance the collective knowledge of the group itself (Table 1). While not strictly sequential, the interaction analysis model suggests five phases for knowledge construction: 1) sharing and comparing of information, 2) discovery and exploration of dissonance or inconsistency among participants, 3) negotiation of meaning of knowledge co-construction, 4) testing and modification, and 5) phrasing of agreement and applications of newly constructed meaning. According to this model, interactions begin by sharing and elaborating ideas (phase 1), leading individuals to identify potential conflicts (phase 2). Individuals build on these conflicts by negotiating meanings and perspectives (phase 3 ); then, they revise their ideas and perceptions (phase 4), and apply their new knowledge (phase 5).

Table 1: Interaction Analysis Model. Based on (Gunawardena et al., 1997), adapted from (Wise \& Chiu, 2011)

\begin{tabular}{llll}
\hline & Phases & Description & Example \\
\hline 1 & $\begin{array}{l}\text { Sharing } \\
\text { Information }\end{array}$ & $\begin{array}{l}\text { Statements of observation, opinion, agreement, } \\
\text { clarification, example or problem definition etc. }\end{array}$ & $\begin{array}{l}\text { "I agree that students' pre-existing ideas are } \\
\text { important to consider. There is empirical support } \\
\text { for this in the misconceptions literature." }\end{array}$ \\
\hline 2 & $\begin{array}{l}\text { Exploring } \\
\text { Dissonance }\end{array}$ & $\begin{array}{l}\text { Identification of areas of disagreement; } \\
\text { clarification of source and extent of disagreement; } \\
\text { providing support for one's ideas in the face of } \\
\text { counterarguments. }\end{array}$ & $\begin{array}{l}\text { "I think what we are disagreeing about here is not } \\
\text { design assessments to drive positive learning } \\
\text { experiences." }\end{array}$ \\
\hline 3 & $\begin{array}{l}\text { Negotiating } \\
\text { Meaning }\end{array}$ & $\begin{array}{l}\text { Identification of areas of agreement across } \\
\text { conflicting ideas; clarification of meanings of } \\
\text { terms; proposal and negotiation of integrating } \\
\text { metaphors and compromise statements. }\end{array}$ & $\begin{array}{l}\text { "I think that if we take an 'expert' as someone who } \\
\text { sees the deep structure of a discipline, then we can } \\
\text { all agree that more than rote memorization is } \\
\text { needed." }\end{array}$ \\
\hline 4 & $\begin{array}{l}\text { Testing and } \\
\text { Modifying }\end{array}$ & $\begin{array}{l}\text { Testing the proposed synthesis against "received } \\
\text { facts," cognitive schema, personal experience, } \\
\text { collected data, and expert testimonies. }\end{array}$ & $\begin{array}{l}\text { "We agreed that peer-interaction is important for } \\
\text { learning, but what about all the research on self- } \\
\text { study and individual tutoring systems?" }\end{array}$ \\
\hline 5 & $\begin{array}{l}\text { Agreeing and } \\
\text { Applying }\end{array}$ & $\begin{array}{l}\text { Summarization of agreement(s); application of } \\
\text { new knowledge; metacognitive statements of } \\
\text { changes in knowledge or ways of thinking. }\end{array}$ & $\begin{array}{l}\text { "I think our discussion has shown that it is not just } \\
\text { the learning materials that matter, but how they are } \\
\text { used. I guess the next question is how to help } \\
\text { students use materials well..." }\end{array}$ \\
\hline
\end{tabular}

Surely, the phases suggested in this model can be rather arbitrary compared to the messiness of interaction (Gunawardena et al., 1997); nevertheless, the rather sequential relationship among the phases is a straightforward way to represent the dynamics of collaborative knowledge construction (Wise \& Chiu, 2011).

\section{Research Site}

Data were collected from a fully online graduate-level education course offered at a large North American research university. Typically, these graduate courses have students from diverse historical and cultural backgrounds, from different geographical locations, and of various ages and professions. The course comprised twelve modules, each corresponding to one week, in which students discussed weekly readings. 
Students were asked to introduce themselves (create their profile pages) and meet with their peers (read and comment on others' profile pages) in the first week and submit their final paper in the last week. In each module, one or two students acted as moderators: they facilitated discussion throughout the week, kept discussions on track, and offered a summary of the week's issues; they provided opportunities for sustained discourse, increased interaction, and rich discussions (Zingaro, 2012). The online discussion occurred asynchronously; the environment does allow synchronous communication through instant messaging, but such activity was not mandatory (nor was it a major communication tool) in this course. 14 students enrolled in the course and worked together as a single group throughout.

It is important to articulate the pedagogical context in which data are collected. The course, Theories and Frameworks for Online Education, was described as an interdisciplinary course engaging with scholarly debate surrounding collaborative learning, sociocultural learning theories, human-centered design, knowledgemedia technologies, and the educational applications of social media. The content of the course comprised basic concepts in, frameworks for, and approaches to the cultural ways of learning, aiming to teach how social media practices reshape online education with respect to two interweaving themes: (1) philosophies of technology and (2) sociocultural learning. In many modules, readings offered contradicting arguments from both ends of the spectrum; not only providing students with a wide range of ideas to support their explanations, but also encouraging them to acknowledge alternative perspectives - though this was not always the case. In addition to the questions posed by the student-moderators (aforementioned), students were asked to critique the readings by drawing from their previous experiences of teaching or learning collaboratively.

It is also important to note that I was not the instructor in this course. The instructor had many years of experience teaching online and I closely worked with her revising the syllabus to encourage students not to take any claims about cultural ways of learning for granted but challenge these perspectives by providing concrete examples from their own experiences of teaching and learning. I never interacted with the students; nevertheless, the students were notified about the research and my presence in the online environment.

\section{Epistemological Frameworks}

Researchers continuously make decisions about finding the most appropriate ways of collecting, interpreting, and presenting data within the given circumstances (Fine, 1993; Maxwell, 2004). Decisions made in this research were constantly reinterpreted and renegotiated by the research team with respect to the overarching goal of capturing and reflecting the validity of the constructed reality. As I have discussed elsewhere (Author, 2014), my understanding of validity is informed by the epistemological and methodological perspectives I follow: I accept validity as the accuracy and truthfulness of research in its attempt to define and describe the events. Socioculturally informed research has been distinctively employing contextual, dialogic, or self-reflexive validity (Charmaz, 2005), and I continue this approach to "facilitate empirical inquiry into social reality in a way that takes into account that the reality is shot through with a mosaic of different realities and that our research is part of the processes forming this social mosaic" (Saukko, 2005, p. 354). Data I present, then, are part of the social mosaic I (along with my research team) formed by triangulating different social realities. Furthermore, when creating the social mosaic, the research team also followed Gunawardena et al.'s (1997) lead during the moments of conflict, which were inevitable due to the subjective nature of discourse analysis: "1) Was knowledge constructed within the group by a process of social negotiation? and 2) Did individual participants change their understanding or create new personal constructions of knowledge as a result of interactions within the group?" (p.412).

Understanding one's experience in the online context is an epistemologically and methodologically challenging task (Baym, 2009; Sterne, 1999) since the online environment as a research context aggravates the challenges of doing good enough research (Hine, 2000). A cartoon published by the New Yorker magazine in 1993 illustrates the difficulties associated with doing online research. The cartoon features two dogs, one sitting on a chair in front of a computer, speaking to a second dog sitting on the floor: "On the Internet, nobody knows you are a dog". There are many ways to interpret the message of this cartoon. For example, while it may refer to the relative anonymity of individuals on the Internet, it may also mean that one can bend his or her identity, pretending to be someone else. In general, the cartoon symbolizes the understanding that identification and online experience - or even dogness - needs to be contextualized with respect to the broader sociocultural context. I further continue the analogy in the cartoon and examine how individuals bring in, draw from, and relate to their offline identities in order to contextualize identity manifestations in online contexts. By so doing, I do not conceptualize online and offline contexts in dichotomy nor do I privilege offline identities over online identities; rather, I accept that online and offline contexts are in flux (Author, 2011) and identity manifestations are constituted through a mediation between the material and symbolic realities of both contexts (Author, 2013a). 


\section{Findings}

\section{Online Personas}

Before I present the three cases, I shall introduce the four selected individuals who are analysed in detail in those three cases. Meet Judith, Manu, Chun-Li, and Ken.

\section{Judith}

Judith is a part-time $\mathrm{PhD}$ student. She identifies herself as Canadian and lives in Seoul with her daughter, where she works as an English lecturer at a Korean university. Her profile page saliently conveys her teacher identity:

I've been teaching English as a second language for the past six years. I have a lot of empathy which I find really helpful in my teaching practice, particularly with Second Language Learners where language anxiety can be a huge barrier to learning. I believe that online communication can be really helpful in overcoming this anxiety - one of the reasons I need to get more comfortable with implementing these kinds of approaches in my classroom.

She also underscores her international work experience in her profile page: "I have had the opportunity to work in Tibet, Saudi Arabia, Taiwan, and Pakistan. I'm in Korea this year living at a temple and teaching English to Buddhist nuns". Judith calls herself a "political-activist" and explains that "this is the reason why [she] live(s) abroad". She says she wants to help people and learn about them at the same time rather than just read about different cultures. She is interested in critical pedagogy and hopes to use such critical perspectives in her dissertation. She says her life is interesting but challenging, particularly for a single mom traveling around the world with her daughter. She shares her pictures with her daughter in her profile page.

\section{Manu}

Manu is a part-time $\mathrm{PhD}$ student and identifies herself as Caribbean-Canadian. She has a big smile in her profile picture and her big, dark brown eyes look into the camera. She describes herself as tenacious and adds that some might call her even stubborn. Manu says she likes being able to help people, whether it's editing a paper or helping a friend prepare class activities. Manu's profile page conveys the message that she is a good student and she is "there" when her peers need her. She is also a preschool teacher and a busy mother:

I run and work at a Montessori School in [a suburban neighborhood]. I still teach to Lower Elementary kids. I have three children and I changed my career to become a teacher because I love children. In my spare time - if I have any - I like learning new languages.

She decided to represent herself as a hard worker, both in her personal and professional life. Her profile conveys the message that she is not only a good student and a good friend but also a dedicated teacher and a loving mother.

\section{Chun-Li}

Chun-Li is from China. She identifies herself as "an international person": she currently resides in Canada but she worked in the United States and studied in UK, where she obtained her master's degree and also taught English as a Second Language (ESL) courses. She says she has been to all of the continents, except Antarctica. Her profile page contains some pictures of her travels, each of which is labeled with the name of the continent on which it is taken. Chun- $\mathrm{Li}$ is a full-time $\mathrm{PhD}$ student and interested in the educational use of digital media. She says she wants to know more about teaching and learning in online environments and this is why she is taking this course. She wants to "experience online education". Chun-Li explains that she wants to stay in academia as a lecturer and teach ESL courses at different universities as she does not feel ready to settle down anywhere yet. She also identifies herself as an artist interested in calligraphy.

\section{Ken}

Ken is a full-time $\mathrm{PhD}$ student and identifies himself as British. He calls himself an "economic migrant", lived in many different places in Asia and taught EFL for 16 years to make money. He is currently working as a lecturer in another department. He is interested in using social network sites for teaching and learning:

I have been trying to integrate social media into blended EFL and EAP courses. I use twitter, facebook, LinkedIn and academia.edu as my personal learning network (PLN) and encourage 
my students to cultivate their own PLNs. I am looking forward to enhancing my understanding of using social networking in online learning.

Ken is six years old in his profile picture, and he explains that the picture is a reminder that he is back to school. This is his first online course and he is "still adjusting to being a full-time student but [he] love[s] learning and ready to study as hard as [he] can". He says animals are his passion and he and his wife volunteer at a local animal shelter. Ken's profile page includes aspects of both a teacher and a student. His online self conveys the image that he is an experienced teacher and a hard-working student who is also dedicated to his personal interests.

\section{Identity Manifestations and Knowledge Construction in Online Learning Environments}

Here, I present the three cases. Please note that in the excerpts below, I do not consider the quality of rigour or pedagogical value of discussion with respect to the aims and goals of the course nor do I judge whether individuals' opinions are appropriate or whether they are somehow right or wrong. My sole goal is to explicate the ways in which identifications are enacted and how these enacments interact with knowledge construction.

\section{Case 1: Different Individuals, Different Identifications}

This week, the class discussed the educational use of web 2.0 and social media. The student-moderators initiated the discussion by asking whether social media applications can fulfil their promise or they are yet another tool that has failed to live up to the hype. The discussion took place in two threads, whereby in the first thread students discussed their experiences of using social media in teaching/learning while in the second they discussed "good examples" provided by one of the weekly readings. Nine students participated the discussion and produced 26 notes in the first thread whereas all 14 students joined the discussion in the second thread and produced 75 notes. Excerpts provided below are from the first thread; no instance of knowledge construction is identified in the second thread despite the large number of notes.

Judith was quick to join the discussion. Only two of her peers exchanged their ideas thus far, producing notes at the level of phase1: they were sharing their initial ideas and comparing understandings. Judith posted the seventh note. The choice of identification is virtually limitless, yet Judith enacted her "political-activist" identity. She drew attention to political issues as she deconstructed the social and political aspects of using digital media in schools:

Thank you [anonymous student 2] for bringing social media and online culture to the table. I agree with you that Hofstede's attempt is downright wrong. Social media has made the culture exchange so simple and frequent that different cultures are blending together like never before. Culture itself is unlike what Hofstede says shaped by the influence of social media. ...

... Of course, this all makes me think about the power exercised by governments and politicians. What we can know is shaped by certain ideologies and we cannot comprehend this because we are part of this very same ideology. And by saying this, I don't only mean dictatorships like China or North Korea, I also refer to "democracies" like the US and Canada. We can only hope to benefit from the use of social media in schools. So, hopefully one day the online culture, as [anonymous student 2] mentions, will free us too. ... I think the readings don't take into account how knowledge in social media can be manipulative. I am looking for other peer reviewed journals discussing these perspectives.

Judith's note starts with what Gunawardena et al. (1997) identify as "phase 1: sharing information" in their interaction analysis model. Then, with the second paragraph, Judith challenged the perspectives offered in weekly readings by articulating her concerns about the tyranny that social media creates and invited her peers to consider the motives behind the knowledge produced in social media (phase 3).

Judith's rather controversial criticism of social media radically altered the focus and the mode of the discussion. In response to this note, Chun-Li enacted her teacher identity to make sense of the assigned readings. She embedded her disagreement with Judith in her teaching experience and explained how she benefited from using social media with her students. Chun-Li's attempts to identify and clarify her disagreement typifies phase 2: exploring dissonance. According to Chun-Li, students should be encouraged to use such technologies since they are particularly useful for vocabulary learning (phase 3). She further elaborated on her disagreement with Judith based on her own experience of using social media:

... For example, in traditional Chinese culture, power differences can be large. I was brought 
up in this culture, where juniors are expected to respect, even obey orders from seniors. This culture are $[\mathrm{sic}]$ undergoing noticeable re-shaping when a chat program like a mobile version of Facebook equivalent is widely adopted in China in recent years. Power dominance are [sic] reduced when juniors are provided with tools to speak up equally. Judith, I see what you mean and we should keep fighting breaking down this cultural dominance.

It is through her personal experience that Chun-Li was able to take a different approach to the notion of power and looked for reconciliation with Judith's perspectives on social media (Phase 3). In other words, it is through her disagreement that Chun-Li was negotiating her ideas and looking for areas of agreement. Other students joined the discussion and supported Chun-Li's perspective. For example, a student wrote:

Chun-Li, I totally agree with you. I have a friend who I talk with through social media. Face to face he is extremely shy so we do not chat as freely as we do online. Technology has indeed 'transformed' our relationship. ... I think that this would also be the case for shy online learners, they have more of a chance to (or are more likely to?) voice their opinions without the social barriers that they have face to face. It could be liberating in other cases too, not only in Chinese context.

Ken directly responded to Chun-Li's note and raised a different kind of concern regarding the educational use of social network sites; that is, the issues regarding privacy and security. Drawing from his teaching experience and based on the assigned readings, Ken summarized:

Judith, Chun-Li, [anonymous student 3], it's valuable for us to disagree with each other's views so discussion can continue. But I am not going to agree or disagree because I want to point out something that we all should be careful as teachers. I thought my students could interact with each other on Facebook, beyond the classroom walls. But, it was too open, it wasn't safe enough. I certainly felt some of my students were uncomfortable sharing personal information. There must be a balance and it is our duty as teachers to find it. Judith, yes, I see your point but in my experience I am concerned with more practical issues.

Ken enacted his teacher identity and introduced a new perspective regarding the educational use of social network sites. His proposition regressed the knowledge construction back to phase 1: sharing information and exploring ideas. Discussion can regress when "segments [are] dominated by lower [knowledge construction] phases than the previous segment" (Wise \& Chiu, 2011, p. 449). Regression can be a good strategy when students search for points of agreement or compromise. Indeed, returning back to phase 1 enabled Ken to search for areas of agreement across conflicting ideas. He did not necessarily disagree with or oppose the ideas articulated in previous notes; rather, he negotiated his particular concerns regarding the educational use of social media (Phase 3).

After Judith's radical criticism of social media, the discussion became that of exploring disagreements and searching for points of agreement. Put differently, the discussion progressed and regressed between phases 1 and 3. Judith returned back to the discussion and agreed with Ken's concerns of her note. She provided an example from her experience and provided a point of dissonance (Phase 2):

Ken, I can see where you are coming from. Last semester I tried using Facebook. I asked my students to interact with each other in English. But guess what? They didn't want to write in English because they worried about making grammatical mistakes. Aren't we all do anyway? :) ... They said Facebook is not "safe" to communicate in English because everybody can see their mistakes. Isn't it a very interesting way to think of safety? I think we all are worried about safety but what safety means differs from individual to individual. What do you think?

While Judith enacted her teacher identity in her response to Ken's ideas, she re-enacted her political-activist identity and referred back to her concerns regarding political aspects of using digital media. She continued:

I am not disregarding my students' point of view. I understand them, it is for sure an issue of safety in terms of social security or personal satisfaction. ... My concerns for safety are not less valid or less important, neither are theirs. And this was my point. Why would they worry about making mistakes to begin with? They are learning English and they are supposed to make mistakes, learn from their mistakes. Why would they feel insecure? It is because the 
idea that everybody should read/write English like a native speaker. And this is partly what I meant. So, don't you think we all described the same thing albeit with different words?

Judith's last sentence is a rhetorical question that synthesised the points of disagreements into a point of agreement. With proposing an agreement, Judith progressed the discussion to phase 4: testing and modifying. Manu responded to Judith's last note, enacting her ethnic identity:

No one should underestimate the role of general belief systems by any means. As a CaribbeanCanadian, I feel your students Judith. Even now, I am freaking out as I am typing this. [Anonymous student 5], have you read any Caribbean jokes on social media? I am freaking out about making mistakes, freaking out that I am not going to be judged or labeled as notCanadian. You know what I mean? In a class of multi-national students, a good understanding of 'equitable and just world' is definitely mush [sic much] needed. It requires a completely different and more comprehensive approach. ... Yes, it is about security but it is about ideology at the same time. We desperately need a more democratic dialogue, where cultures are represented in curricula, not only in terms of how they are different or deficient. ... Yes, it gives me voice and I can join the discussion but it is not the whole story. I agree with Judith that it is ideological, it is about power structures.

In the excerpt above, Manu drew from Judith's comments regarding safety. She shared her opinions about how general belief systems affect the image of Caribbeans in social media (Phase 1). She discussed how teachers' and other students' ideas and opinions about Caribbean people are shaped by such images. Manu rephrased Judith's ideas based on her experience, concluding that safety should be considered in relation to power structures (Phase 5).

Judith built on Manu's experience and provided her own experience: she exemplified how people from Middle East appear in Canadian media and how Western people appear in Far-East Asian media. She further provided her opinion about how mainstream media influence both public opinion and public policies regarding schooling and education (phase 5). Chun-Li agreed with both Judith's and Manu's opinions and, enacting her national identity, she extended the discussion by her understanding:

... I experience this, I am being stereotyped. There is this understanding that I have to be a certain person. They stereotypify [sic] me depending on what they think of me. They start guessing by looking at my face, by looking at my name. ... You are already defined; your role is already defined for you and you play it and get along with people.

She, then, suggested a completely new perspective to consider:

I agree with you all that education and social media play a significant role in instilling the deterministic view of cultural traits and supporting the deficit theory. Manu, Judith, your comments about how education and mass media and social media stereotype people and cultures resonate with me. I think this is how neo-colonization is facilitated. We can all agree that stereotyping is unhelpful and puts the learner (and teacher) at a disadvantage.

For Chun-Li, stereotyping individuals or cultural groups in social media may be related to neo-colonialism (Phase 5). Ken supported Chun-Li's comments on neo-colonialism but questioned whether this problem is specific to digital media or whether it is a general concern about the "world we live in". Ken, enacting his ethnic/national identity, explained that he was being stereotyped as a regular white man when he was living in South Asia (Phase 5). According to him, since the advantages of social media are evident and the social media is here to stay, the question should be how to use digital media without marginalizing cultural groups (Phase 5). Another student agreed with Ken as she was providing her example of being stereotyped as White female (Phase $5)$.

In this case, individuals made sense of the subject matter with respect to their identities; that is, identities provided situated meanings by which knowledge was co-constructed. The role that identities play in this process is particularly evident when the outcome of this group discussion is considered in relation to the week's readings: the assigned readings did not concern critical perspectives on social media, but the knowledge constructed by these students was highly critical of the educational value of social media. Judith's politicalactivist identity played an important role in this outcome. Judith initiated the discussion by introducing such critical perspectives and, despite Chun-Li's counterarguments, articulated her opinions and directed her peers' 
attention to issues surrounding cultural beliefs and social media.

\section{Case 2: Same Individuals, Multiple Identifications}

This week, the topic was teaching and learning in hybrid and blended courses with Computer-MediatedCommunication (CMC). The student-moderators started four threads, each of whose starter questions focused on a different aspect of teaching and learning with CMC. All 14 students participated in the discussion and engaged in lively discussions, producing relatively equal amounts of notes in each thread. Instances of knowledge construction are identified in all threads; however, only the third thread typifies the ways that individuals can utilize different identities at different phases of knowledge construction. In the first and second threads, discussion revolved around the learning theories, and thus the impact of identification remained minimal. The fourth thread was concerned with the issue of access to technology; precisely, with the issue of unequal distribution of technologies across schools. Despite the profound role cultural backgrounds and identification played in this thread, it was not selected as a case since not all four personas enacted different identifications at different phases of knowledge construction nor did all of them took active role in the development of this thread. The excerpts below are from the third thread as it typifies the case best.

The thread comprised 33 notes, focusing on types of electronic communication. The meta-data indicates that the discussion progressed slowly compared to the other threads; however, it became the centre of attention towards the end of the week. The discussion began in a sharing-information mode: the first 11 notes went back and forth between phase 1 and phase 2, suggesting that students tried to develop their understanding before critically engaging with others. Ken posted the twelfth note, where he enacted three different identities in a single note:

... As a student, I would much prefer asynchronous interaction because I need time to think. As a teacher, I think having synchronous interaction is important. There is an energy and flow about synchronous communication that really helps students. As a researcher, I think we need to account for differences and styles and therefore we cannot really say one is better than the other. They are just different formats that teachers must utilize in order to accommodate as much differences in the learning group as possible.

Continuing the focus on phase 1 and 2, Ken shared his opinion regarding different communication types with respect to his experience with $\mathrm{CMC}$ as a student, as a teacher, and as a researcher. Without advancing the cognitive level of the discussion, Ken merely articulated his thoughts (phase 1). A student replied to Ken's note and agreed with his perspectives. On the thirteenth note, Judith joined the discussion.

Judith directly replied to Ken's note and enacted her teacher identity. She further continued Ken's ideas and articulated that she works to to provide a multitude of resources and opportunities for her students to succeed in a way that works for them (Phase 1). In the same note, Judith also reacted to one of the articles in the assigned readings; in particular, she disagreed with a claim that Asian students underachieve in online learning courses compared to their Western counterparts:

... But I completely disagree with [the authors] in [reading 1]. I am not buying their claims. Instead, I suggest looking at the murky area of "control" (for lack of a better word) that results in the shift from a traditional learning environment to an online learning environment. ... In courses I teach, I attempt to employ constructivist techniques to motivate and empower students. This is the reason why I disagree when [reading 1] says Asian students are not participating because it is against their culture. Why? Because, one of the requirements of the course is a blog (with a topic of their own choosing) and students are grouped into smaller blogging communities (based on similar topics) to comment and interact on each other's blogs. And I am very confident that all of my students are participating. They are not shy at all. ... They are as comfortable as anyone can be. Many students write about issues related to themselves, but do not necessarily always conform to academic conventions. But this doesn't mean that they are not participating or it is against their culture! And they are NOT underachievers.

I feel like I am repeating myself for the millionth time but [reading 1] is a good example of how people look at certain cultures. But, I don't think it is a question of culture, whether one is from Korea or Canada. The question is not who is shy and who isn't. I think the real question is, in a constructivist online learning environment, how does one negotiate what is proper (in keeping with principles of academic discourse) in a highly diverse audience without 
interfering with principles of constructivism (democratic, student-centred, autonomy, etc.)? Sorry this is poorly worded as I am struggling with how to express this question. ... However, my point is that in an environment where people feel safe and comfortable, they participate equally and succeed equally. Period.

Enacting two different identifications simultaneously, Judith, as a teacher and as an activist, extensively articulated her disagreement with the weekly readings. She suggested that whether her students are or are not shy, they have no problem engaging with each other when they feel safe and comfortable; thus, anyone can be successful if they are somehow given enough opportunity to participate. While Judith simply shared her opinion (phase 1), her note provoked a discussion about culture and participation.

Ken responded to Judith and suggested that certain concepts should be further clarified. He proposed that Judith's criticism may not be entirely true as she argued. Seeking for a clarification of disagreement and trying to identify areas of disagreement (phase 2), Ken explained his understanding based on his teaching experience in South Asia:

Judith, I think [there is] nothing wrong with that claim. It is certainly true that most of my students were hesitant to participate. But this has something to do with who is present in that particular conversation. They were not comfortable talking to me or other Western teachers. So I agree with that claim in a sense. It doesn't mean that they are less clever but it doesn't change the fact that they participate less compared to others. So, what do we do?

Ken continued articulating his perspectives by answering his own rhetorical question. He enacted his teacher and ethnic identity to further materialise his counterargument and explore the dissonance:

I see where you are coming from because I taught in many Asian countries, including Korea among many others. I also understand why you are angry but there is a limit to what you can say if you have a predefined political agenda. ...

The political aspects of constructivism are surely very interesting. In a nutshell, the political angle is essentially worried with, who is influencing, mediating and controlling this process if knowledge is socially constructed. You are absolutely right there. But the online environment is where this kind of communication becomes less an issue because students are writing to an audience of their peers, so they become more empowered - if I may use your own words. And if they are participating less, and this is what [reading 1] shows us, what is wrong with that claim? Others can correct me if I am wrong but, Judith, I feel that you are slightly missing what [the authors] meant. ... You should not disregard what context means. What do you all think?

Because Ken is familiar with the context in which Judith is currently teaching, he was able to not only question the merits of Judith's criticism but also look for areas of agreement between their perspectives (phase 3). For example, Ken acknowledged Judith's position that the social construction of knowledge is subject to political agendas; yet, he also indicated that what context is open to debate as a point of reconciliation. Using the concept of context to negotiate the dissonance sparked a series of notes exploring Judith's and Ken's conflicting perspectives.

Chun-Li answered Ken's call and joined the discussion, enacting three different identifications in a single note: a Chinese, a student, and a researcher. She reiterated points of agreement and disagreement between Judith and Ken (phase 3). According to her, as a Chinese, it is true that most Asian students prefer to be silent because it is likely that they need more time to feel comfortable. As a researcher, Chun-Li pointed out that questioning whether Asians are underachievers is not as productive as why Asians may feel uncomfortable. She suggested that Asians may feel uncomfortable because they, perhaps, believe that they are going to be judged by their level of English rather than their intellect. She also thanked her peers because they helped her to "feel comfortable enough to join this conversation". Then, Chun-Li switched gears in her note and drew ideas from one of the readings:

... But I actually want to point out something that [anonymous student 1] mentioned above. We have different "selves" as [reading 2] explains. We have different "front stage and back stage behaviours". Which means that you can not understand context without thinking of these different front stage and back stage selves. ... I remember participating in online forum groups 
where I hid behind masks and interestingly, at the end of the day, it is only when we held actual meetings that I felt safe. How would you explain my situation in that context, then? People, regardless of their cultural background, will develop their own context as they participate in online discussion.

Chun-Li incorporated arguments from weekly readings with her own experience and suggested a new way of thinking about context (phase 5). Manu used Chun-Li's idea to justify her experience of participation. She enacted her ethnic identity and suggested that as a Caribbean-Canadian, she needs to feel safe before she can share her opinions. Referring back to assigned readings, and drawing from her own experience, Manu articulated that sense of comfort and participation should be conceptualised as a more general problem regarding context. Further exploring the relationship between culture and participation, Manu asserted (phase 3):

... It is interesting because I lurk a lot more than I post. In fact, I quite enjoy reading others' comments and I assimilate their ideas into my own. I digest them in a sense. It requires a lot of mental processing - so lurkers do a lot more than people think. But, besides that, the reason I lurk is that I need to feel comfortable before I share. I need to feel part of the community. Judith, I know you will disagree with us, but I am with Ken and Chun-Li in this. Believe me this has nothing to do with culture, it is just all too human to seek for that sense of safety. Lurking or not, people need that feeling. In my understanding, this is what makes up online context. ...

Manu shifted her identification as she continued her note. Utilising her teacher identity, she further suggested:

... That context is an interesting to think about. I would also argue that it seems that we have an essential identity or a personal identity and we choose to express different facets of our identity based on the social features of the group we are in. Social identity would be informed and influenced by the group. This is what different selves mean to me. I also agree that culture influences how individuals interact in different contexts. The immigrant youth I work with largely prefer interactions with their close friends. Canadians on the other hand prefer interactions that are deeper but more social. What makes the context when these kids are in the same place? I mean, if we all develop our own context, what happens when these two groups of kids start interacting? I am not sure how to explain what the context is in this case.

Manu synthesised Chun-Li's idea and applied it to her experience, questioning the merits of her proposal (phase 4). Manu did not seem to disagree with Chun-Li; rather, she seemed that she was genuinely trying to make sense of her experience as a teacher in her school.

Ken quickly responded to Manu. He enacted his ethnic and professional identity in his relatively short note. After he rephrased Manu's ideas and reinforced his position on the relationship between culture and participation, Ken added that in order to participate, he needs to feel comfortable too. Using a metaphor to further his thoughts, he continued (phase 3):

Great points you make Manu - I agree that delving into culture makes us more confused but we should just keep digging more. I found this on Google and I like it a lot. It says the concept of culture is like an iceberg. My take on that metaphor is that differences we see among us is just the part above water. What unites us is much bigger but unfortunately it is not easy to see, so it is the part below water. If I dare, one thing I can tell you as a teacher is that focusing on similarities rather than differences would help you see your context much better.

Ken's use of metaphor shifted the focus of the discussion from context back to the relationship between culture and participation.

It was towards the end of the discussion that Judith joined the conversation again. Enacting her professional and ethnic identity, she reappraised her thoughts:

... Yes, I see your points with the political agenda and I try to be careful about its limitations with bias. I am a sensitive person ... and I may overreact. ... I in fact have to react because I don't want stereotypical comments ... to affect my relation with my students, as a Canadian teacher teaching to Koreans. ... I think the sense of comfort or the sense of community or the sense of safety - or the lack of it - should not be considered in relation to race or nationality 
or gender etc. since every cultural group has something that can make them feel unsafe. I taught in many different countries and I can surely tell that every cultural group value different things and worry about other things. I also have certain things that I worry about before I feel I can share my thoughts and feelings. ...

Judith acknowledged the counterarguments that perhaps there may be a link between culture and participation and that she may have misinterpreted the readings (phase 3). Building on the counterarguments and drawing from her experience, she continued:

... Oh, I loved the iceberg example. Nice one Ken. In a sense, it explains why I ranted in the beginning. If we label people and look at the numbers, we will find different cultural groups do different things. But it doesn't tell us why there are differences to begin with. We should see our students as equal participants and try to foster equality after they start their interacts[sic]. I know it doesn't read like that but that's what I meant in the beginning. It is a perfect example.

Judith applied the metaphor to her experience as a teacher and used it to summarise the points of agreement thus far (Phase 5). Chun-Li built on Judith's ideas and enacted her Chinese, student, and teacher identifications. As a Chinese person who studied and worked in both the UK and Canada, she appropriated Judith's ideas to her experience (phase 5). Chun-Li explained that focusing on differences among cultural groups can be a disadvantage for her because:

... in a group work, like wiki-based environments ... changing another's work without permission is intimidating since I believed that it is like saying that you think that what you have to say is more important or more valid than what someone else has to say. ... Now [I] feel more comfortable with working in wiki-based applications. Therefore it will be misleading if articles say Chinese people are not comfortable working with wikis or prefer not to participate in discussions. ... I know how my students feel ... so I always provide [them] other opportunities to work with people in order to accommodate their needs.

Chun-Li rephrased the group agreement (phase 5) that while cultural aspects can indicate certain concerns, culture by itself is not strong enough to explain patterns of participation. Another student replied to Chun-Li and asked her to compare her experience between the UK and Canada before the moderators wrapped up the discussion.

This threaded discussion typifies the ways that individuals can utilize different identities at different phases of knowledge construction. For example, Ken enacted his student, teacher, and researcher identity for sharing information (Phase 1). Later, he enacted his teacher and ethnic identity for exploring dissonance (Phase 2); then, he enacted his ethnic identity for negotiating meaning (Phase 3). Similarly, Judith enacted her teacher identity for sharing information (Phase 1) and negotiating meaning (Phase 3) while she enacted her ethnic identity for agreeing and applying (Phase 5). Chun-Li enacted her ethnic identity for sharing information (Phase 1), exploring dissonance (Phase 2), and negotiating meaning (Phase 3). She also enacted her student and national identity for testing and modifying (Phase 4), as well as for agreeing and applying (Phase 5). Manu, on the contrary, enacted only her ethnic identity for negotiating meaning (Phase 3 ) and for testing and modifying (Phase 4).

The passages above also epitomize the ways that individuals can use the same identities at different phases of knowledge construction. For example, while Ken enacted his student identity for sharing information (Phase 1), Chun-Li enacted her student identity for agreeing and applying (Phase 5). Similarly, while Ken enacted his ethnic identity for exploring dissonance (Phase 2), others enacted their ethnic identity for negotiating meanings (Phase 3), testing and modifying (Phase 4), and agreeing and applying (Phase 5).

\section{Case 3: Different Identifications, Same Meanings}

This week, week 10, the class discussed the impact of social and cultural issues in online and distance learning settings. The student-moderators began by summarizing the main arguments put forward in weekly readings and asked how cultural perspectives and differences resonate with their professional experience. This rather generic question broadened the focus of discussion and yielded the highest number of threads across weekly discussions. The discussion spread over seven threads; however, the number of notes within each thread was relatively small, perhaps due to the relatively high number of threads. Only in two threads were instances of knowledge construction identified. All 14 students were active this week and they all engaged in all threads. 
The focus of discussion in the thread being analysed here is on the diversity of learning contexts. It is the second most populated thread for the week with 24 notes; however, according to the automated log data, the thread has the highest word count and time-spent-online, suggesting that students paid most of their attention to this discussion.

Three students articulated their perspectives (Phase 1) before Judith joined the discussion. The third note is worth quoting at large as it sparked an exchange of ideas around the issue of cultural diversity. Enacting her professional identity, a student wrote:

... I read [the weekly reading] differently. Here is why. I have worked with students from different cultures, students who are first generation Canadians whose parents have migrated here; students whose parents are asylum seekers; students with a range of learning difficulties. I am convinced that teachers and educators have negative assumptions about these students as if they know what's needed for them. I am not sure if diversity can ever lend itself to equality in classrooms because teachers don't know what they are dealing with. Do you think students expect that teachers will understand their cultural differences and requirements?

The rhetorical question at the end of this note became a focal point from which others departed by articulating their perspectives and experiences. Judith was the first to react; she acknowledged that teachers' beliefs about cultural differences are important:

I agree, [anonymous student 1], that teachers have assumptions about students. ... In my experience, it is very difficult to change other teachers' beliefs about cultural differences. It is because the term 'cultural diversity' is often misused (especially by stakeholders) - as though it is more important that teachers, educators, school principals, the director of education, etc. say that they have well thought out "cultural diversity" ... than they actually understand it. ... This is the reason why teachers have misconceptions about their students' cultural needs. In my experience, teachers are just worried about ticking the boxes off in official reports when it comes to cultural diversity.

Similar to the student in the previous note, Judith enacted her professional identity. However, while she agreed with the issues identified in the previous note, she also provided an alternative perspective (Phase 1). As a teacher, Judith believed that cultural diversity means more than addressing teachers' negative assumptions. As she continued articulating her understanding, Judith started enacting her maternal identity, explaining that an authentic learning context requires active dialogue between parents and teachers:

... I think that it is not only the responsibility of the teacher but also the parent to help establish an equal learning environment for all students. As stated in previous posts by others and you, as parents we want to make sure nobody is being left out, we want to make sure we are being inclusive and doing our best to help teachers to better accommodate our kids' needs. How does a teacher provide authenticity just by herself? How does a parent expect teachers to do everything?

Enacting both her professional and maternal identity, Judith identified a source of disagreement based on her experience (Phase 2). It is through this type of identification that she was able to provide a counterargument; that is, the tension between diversity and equality is not only about teachers' attitudes but also requires parents' active involvement. Even though Judith's maternal identity was not salient in her previous notes, being a mother was one of the identity traits to shape the learning experience in this particular group discussion.

Manu responded to this message, also enacting her maternal identity along with her teacher identity. She built on Judith's perspective by further elaborating her experience:

I totally agree with you both - though you have different points on teachers. I appreciate the usefulness of taxonomies in general, but think human nature is too messy to be classified. ... $[F]$ or managers and principles inclusivity is about numbers, but teachers have nothing to do with that. Diversity is not about numbers ... As a teacher, when I think of diversity what comes to my mind is students who not only have different learning needs but also [students] who come from diverse social backgrounds. Learning diversity encompasses diverse learners with different academic needs, such as students with disabilities and English language learners - such as my kids. But then, I see a big mismatch between the articles and my kids' schooling. 
I wonder if the authors of these articles have any kids or ever taught at schools. Judith is right in a way, how can a teacher do it all?

Manu acknowledged both sides' perspectives on diversity and the capacity of teachers to recognize and appreciate diversity in the classroom. By so doing, she attempted to clarify differences between Judith and Anonymous Student 1, and tried to link the points of disagreement between the two (Phase 3). She then incorporated her understanding of diversity based on her experience as a teacher and a mother. Manu continued:

Maybe a different approach would be to clarify to what extent learning differs by calling it culture. Although we can call on a number of stock words - nationality, race, gender, ethnic group, social-class, sexual orientation, etc, etc, etc - how they impact on learning is not straightforward. One thing is for certain; students differ in one way or another, but is it enough to make claims on learning? Whether it be race, class, gender or language this thing we know as culture helps give students identity. That's all. Let's agree on that.

Tackling the relationship between culture and learning, Manu suggested a new lens for understanding the disagreement and started to develop her own hypothesis in order to unite strands of consensus (Phase 4). Then, she continued:

But [the weekly readings] argue that it has an impact on performance, learning styles and learning rates, learning experience and expectations, attitudes and achievements. Isn't it downright wrong? How could you categorize people so easily based on the ideals of culture? This is an open-ended question for you all; can you simply categorize people in your daily life just like that? Let me tell you; [the weekly readings] assume culture [to be] monolithic. Like the principles and managers you mentioned above, and the ones that I've been working with so far, I believe [the authors] try to ensure they 'deal with' the diversity. They just idealize it; it is far from real-life situations. Simple is that...

Manu tested her own hypothesis by providing rhetorical answers to her own questions based on her experience as a teacher (Phase 4). She suggested that the weekly readings, perhaps, offer an idealized understanding of diversity and thus do not reflect real-life situations.

Two other students replied and agreed with Manu, enacting their professional identities. Ken was the third replying back to Manu. He enacted his ethnic and professional identity, and picked up on Manu's new proposal of the lack of congruence between idealizations and real-life situations in learning and teaching. He agreed with Anonymous Student 1, Judith, and Manu, and tried to reconcile differences among them by suggesting that as a teacher, he believes readings are "just idealized scenarios" and that there are "unavoidable power tensions between cultural groups" (Phase 3). Ken continued enacting his professional identity:

I'd agree, culture is difficult to quantify, in addition, students differ so much within their respective cultures so it is not unified. The whole aspect of the impact of culture on teaching and learning, how we accept, accommodate and celebrate student diversity is a fascinating element of our day-to-day job as teachers. This is what we all agree so far.

Ken's cohesive view of disparate ideas led others to build on agreed facts, transitioning from debating to knowledge construction. Chun-Li was the second one to reply. She enacted her ethnic identity and further discussed "the idealized scenarios" by providing examples from her learning experience:

I did my MA in UK and I felt more Chinese then[sic] ever. ... But it doesn't mean that I was quiet or shy. Idealized scenarios? Yes! But then you are also right Ken that all of my teachers, lecturers, instructors, professors - what ever you call them - accommodated differences. But how do they accommodate? I think we have to understand what we mean by difference. Difference or diversity is not about where we were born or what kind of skin color we have. Diversity or difference is not about geographical location. Where I was born, where I studied, and where I am right now are completely different locations. So, where do I fall into?

Chun-Li built on Ken's summary and exemplified the current understanding based on her experience, testing the proposed synthesis (Phase 4). She continued: 
... again, how do teachers accommodate these differences? Maybe [reading 1] offers an answer for dealing with different cultural groups: an 'inclusive' approach, which not only incorporates cultural perspectives from minority groups but also challenges the dominant model. I think this explains what I faced when I was in UK. I found that the lecturers were good at allowing individuals to express themselves. In my experience this allowed inclusivity because cultural practices are often shaped by individuals and their own dynamic. I look forward to future discussion.

Chun-Li was able to draw from Ken's summary, and bring together her experience and the readings to construct knowledge (Phase 5). According to Chun-Li, "if diversity is thought of as a matter of individuality, then the issue of the inclusion or exclusion can be better understood" (Phase 3). Ken enacted his student identity in his response and noted the importance of a learning community:

As classmates we want to make sure nobody is being left out from the discussion, we want to make sure we are being inclusive in all our discussions and activities and doing our best. Therefore effort also needs to be made on the students part, on our part. Perhaps, we can consider trying what [reading 1] suggests and help each other, especially those who are excluded. In sum, I think the key is being aware of any exclusiveness and making the effort to establish a community.

This particular note from Ken received great attention from his peers (indeed, this is the most replied-to note throughout the course according to the automated-log data) and constituted a point of agreement for the whole class (Phase 5).

Summarizing the weekly discussion and affirming Ken, Manu synthesized that "educators should teach their students ways to foster diversity in all its forms (ethnic, sexual, gender, learning styles, etc.) and create a sense of community to create inclusive educational contexts" (Phase 5). Judith built on this and summarized that "most of us have the best of intentions as teachers and parents, but as all of you put it so well, life... happens!".

\section{Discussion}

This research examined the role of identification in knowledge construction when individuals engage in group work in online learning environments. The three cases represent three different and unique ways that identities play a role in collaboration and knowledge construction. In the first case, individuals utilized different identifications to make situated meanings in their interpretations of the weekly readings. Furthermore, when individuals enacted certain identifications, their peers accepted them as such and engaged with them accordingly. In the second case, individuals enacted multiple identifications at once. In the third case, individuals had similar perspectives and agreed with each other's conceptualizations while enacting different identifications.

Taken together, these three cases provide an initial understanding for the role that identifications play in group work or collaborative learning activities. The results show that individuals bring various identities into the online discourse and utilize their different identifications under different circumstances for different reasons. For example, what it means to be "a teacher" or what it means to be "Asian" or "Canadian" have different meanings for different individuals under different circumstances and thus have different consequences for different individuals. This should be considered in relation to the work described in Ligorio et al. (2013), where the relationship between different identity trajectories and knowledge construction remained in question. The present research offer that individuals' unique identity trajectories determine the nature of the discourse and shape the process of knowledge construction. The three cases also show that individuals do not experience online learning through just one identification category. Instead, these classmates flexibly and simultaneously used multiple identifications to collaborate and learn. It would be misleading to collapse these multiple, distinct identifications into single constructs.

The three cases also provide an initial understanding of the role that identification plays in the process of knowledge construction. Currently, CSCL research suggests that knowledge construction begins with basic interactions that facilitate the sharing of individuals' experiences (Gunawardena et al., 1997; Ke et al., 2011; Wise \& Chiu, 2011). The present research further demonstrates that once the foundation for common ground is established, meaningful dialogue and collective reflection can take place. Through the process of negotiation, individuals provide detailed analysis or criticism, drawing from their experiences to construct new knowledge. When new knowledge is constructed, individuals develop more nuanced understandings and perspectives. The results reaffirm that "learning through discussions can be conceptualized as developing, challenging, and re- 
conceptualizing ideas" (Arvaja, 2012, p. 99).

When the role of identification in knowledge construction is considered, the results show that identifications are manifested at every phase of knowledge construction. There seems to be no pattern to the ways that identifications are expressed across the phases of knowledge construction. Yet, identifications play a unique role in each phase. While identifications can provide basic information about an individual in phase 1, they can provide more detailed information about individuals and their perceptions in phase 2 . In phase 3 , individuals rely on their identifications to challenge current perspectives offered by their peers or by weekly readings. Individuals then analyze the learning material or the subject matter in relation to their identifications in phase 4 , and explain what they learned from that particular discussion in relation to their experiences in phase 5 . In other words, individuals use their identifications to articulate their prior thoughts in the early stages of knowledge construction. Then, they use their experiences to further develop or challenge the existing perspectives in the middle stages of knowledge construction. Finally, in the final stages, they find common ground and reconsider their thoughts and further explain what they learned in relation to their identities. This can shed some light on the questions raised by the study defined in Ke et al. (2011), where the relationship between identities and knowledge construction is examined quantitatively. The present work suggests a qualitative explanation to such a relationship identified in Ke et al.'s work.

This research corroborates the existing literature of sociocultural learning theories. If learning is an aspect of practice-based identity (Lave \& Wenger, 1991; Nasir \& Cooks, 2009), the results show that individuals have different learning experiences despite engaging in the same group discussion. Identification, according to this perspective, mediates between the social and cognitive aspects of learning in a community:

identities allow a way to understand the intrapersonal dimensions of learning and to capture the ways that learning settings can support or fail to support not just the acquisition of skills and knowledge but also a deep sense of connection with participants. ... [P] articipation in learning settings extends beyond learning ... to the very definition of who one is and who one is in the process of becoming through participation. (Nasir \& Hand, 2008, p. 176)

Findings of this research concurs this perspective by demonstrating that individuals utilize different identifications to make situated meanings and that these meanings relate to knowledge construction in online group discussion. Put differently, if learning is simultaneously a personal and social process (Cole, 1996; Holland et al., 1998), this research shows that cultural practices determine the social fabric for collaboration, where one identifies himself or herself in relation to others.

Overall, the findings of this research suggest a further explanation to the intertwining relationships among cultural practices, identification, knowledge, and collaboration. For learning scientists and CSCL community, the concept of idea diversity is essential for knowledge construction and group work (Scardamalia, 2002; van Aalst, 2006; Zhang, Scardamalia, Reeve, \& Messina, 2009). The simplest explanation is that "by attempting to consolidate a range of ideas on a topic, [students] can improve their understanding" (van Aalst, 2006, p. 282). However, by and large, CSCL researchers studied ways to promote idea diversity through increasing the capacity of online discussion forums due to the lack of social support and cognitive scaffolding inherent in these environments. This work suggest that attempts to support idea diversity can go beyond the affordance of technological medium and that identification can be utilized to support idea diversity when students collaborate. If knowledge is socially constructed (Pea, 1993; Stahl, 2006) and if understanding an idea requires understanding the ideas that surround it (Scardamalia, 2002), the present work demonstrate that identification can help group members with understanding their peers and creating coherency among them. Put differently, this work indicate that identification play a significant role in every step of knowledge construction: it is largely through identities that one can understand others' ideas and that communal knowledge evolves into a new and refined form. Furthermore, when other knowledge building principles are considered, identification can also be associated with epistemic agency. The concept of epistemic agency refers to "the level of complexity at which a student chooses to approach an issue" (Zhang et al., 2009, p. 24). It is essential for negotiating ideas among group members during collaboration (Scardamalia, 2002). The findings show that identification can help with supporting the epistemic agency by adding a layer of complexity to the group discussion, particularly when students are able to draw from and build onto their own experiences. Increasing the intellectual complexity of the discussion while keeping the topic personal helped students with achieving a new syntheses. Surely, more work is needed to make stronger and conclusive claims regarding the role of identification supporting the epistemic agency; nevertheless, the findings of this research indicate that identification mediates the negotiations between personal ideas and ideas of others at a higher level of complexity.

\section{Conclusion}

This research is built upon the idea that learning is simultaneously a personal and social process that requires active participation within learning communities. One approach to understand what mediates between 
the personal cognition and social activity is to explore the role of identifications in a given context (Cole, 1996; Holland et al., 1998) since they provide opportunities for individuals to make situated meanings by incorporating aspects of themselves into the learning practice (Wenger, 1998). This research follows such perspectives and analyses the role that identifications play in group discussions. The results demonstrate that identifications support dialogic and reflective interaction. Far from tangential to the group discussions, identifications are a central part of collaborative meaning-making and knowledge-construction.

This research examined the role of identification in knowledge construction when individuals engage in group work, and the findings provide a further explanation to the intertwining relationships among cultural practices, identification, knowledge, and collaboration. Learning scientists and CSCL researchers have long argued that learning is a dialogic process of collective thinking (Scardamalia \& Bereiter, 1994; Stahl, 2006). Currently, the CSCL community contends that identifications can help support the dialogic nature of online discussions and thus build a greater sociology of learning (Ke et al., 2011; Ligorio et al., 2013). Using individuals' own experiences as a source of learning "can support student agency... by giving opportunities to make personal sense through personal lives" (Arvaja, 2012, p. 86). While the present research affirms the current perspectives, it further explains in detail how identifications play a role in each and every stage of collaborative knowledge construction.

If identification play a significant role in every step of knowledge construction, designing online environments to support identity play can be critical for collaborative learning. As I have argued elsewhere, meanings in these environments can be quite explicitly tied to the context; therefore, lack of personalization could lead to a lack of understanding, and thus lead to disengagement from the learning community (Author 2013). It would be imperative to encourage students to benefit from their personal and professional experience as much as possible. This would be particularly useful in environments using asynchronous threaded discussions due to the lack of social support and cognitive scaffolding inherent in these environments.

The findings should be considered in relation to the limitations of the study. First, while this study provides important guidance toward understanding the role of identification in the process of knowledge construction, this is the initial investigation where much follow-up inquiry is needed. For example, further courses and larger numbers of students could corroborate these findings; interview data could be used for more targeted investigations of possible links between identifications and knowledge. Second, identifications in this study are not analyzed in relation to the concept of power. Examining identifications with respect to power can provide insights into the otherwise hidden constraints of group work or community-building. Furthermore, in this study, identifications are stripped from their social, political, and historical meanings, largely because the aim of the research was not to explore the hidden curriculum of collaborative learning practices. Research with a more critical agenda should consider such meanings in its analysis.

\section{Acknowledgements}

Acknowledgements to my research team here. RAC. Pepper.

\section{References}

Author (2011)

Author (2013a)

Author (2013b)

Author (2014)

Arvaja, M. (2012). Personal and shared experiences as resources for meaning making in a philosophy of science course. International Journal of Computer-Supported Collaborative Learning, 7(1), 85-108. http://doi.org/10.1007/s11412-011-9137-5

Arvaja, M., Salovaara, H., Häkkinen, P., \& Järvelä, S. (2007). Combining individual and group-level perspectives for studying collaborative knowledge construction in context. Learning and Instruction, 17(4), 448-459. http://doi.org/10.1016/j.learninstruc.2007.04.003

Atwood, S., Turnbull, W., \& Carpendale, J. I. M. (2010). The Construction of Knowledge in Classroom Talk. Journal of the Learning Sciences, 19(3), 358-402. http://doi.org/10.1080/10508406.2010.481013

Bakhtin, M. M. (1986). Speech Genres and Other Late Essays. (C. Emerson \& M. Holquist, Eds., V. W. McGee, Trans.) (Second Printing). Austin, TX: University of Texas Press.

Baym, N. (2009). What constitutes quality in qualitative internet research? In A. Markham \& N. Baym (Eds.), Internet Inquiry: Conversations About Method (pp. 173-189). Thousands Oak, CA: Sage Publications.

Bently, J. P. H., \& Tinney, M. V. (2003). Does culture influence learning? A report on trends in learning styles 
and preferences across cultures. Presented at the The Annual Conference of the Association for Educational Communication \& Technology, Anahaim, CA.

Bereiter, C. (2002). Education and Mind in the Knowledge Age. Mahwah, NJ: Lawrence Erlbaum Associates.

Brubaker, R., \& Cooper, F. (2000). Beyond "identity." Theory and Society, 29(1), 1-47. http://doi.org/10.1023/A:1007068714468

Buckingham, D. (2008). Introducing Identity. In D. Buckingham (Ed.), Youth, Identity, and Digital Media (pp. 1-22). Cambridge, MA: MIT Press Journals.

Charmaz, K. (2005). Grounded Theory Methods in Social Justice Research. In N. K. Denzin \& Y. S. Lincoln (Eds.), The SAGE Handbook of Qualitative Research (3rd ed., pp. 507-535). Thousands Oak, CA: SAGE Publications.

Cole, M. (1996). Cultural Psychology: A once and Future Discipline. Cambridge, MA: Harvard University Press.

Creswell, J. W. (2006). Qualitative Inquiry and Research Design: Choosing among Five Approaches (2nd ed.). Thousands Oak, CA: SAGE Publications.

Engle, R. A. (2006). Framing Interactions to Foster Generative Learning: A Situative Explanation of Transfer in a Community of Learners Classroom. Journal of the Learning Sciences, 15(4), 451-498. http://doi.org/10.1207/s15327809j1s1504_2

Erikson, E. H. (1968). Identity: Youth and Crisis. New York, NY: Norton.

Fairclough, N. (2001). Language and Power (2nd ed.). London, UK: Longman.

Fine, G. A. (1993). TEN LIES OF ETHNOGRAPHY: Moral Dilemmas of Field Research. Journal of Contemporary Ethnography, 22(3), 267-294. http://doi.org/10.1177/089124193022003001

Gee, J. P. (2011). An Introduction to Discourse Analysis: Theory and Method (3rd ed.). New York, NY: Routledge.

Gramsci, A. (2000). An Antonio Gramsci Reader: Selected Writings 1916-1935. (D. Forgacs, Ed.). New York, NY: Schocken Books.

Gunawardena, C. N., Lowe, C. A., \& Anderson, T. (1997). Analysis Of A Global Online Debate And The Development Of An Interaction Analysis Model For Examining Social Construction Of Knowledge In Computer Conferencing. Journal of Educational Computing Research, 17(4), 397-431.

Gutiérrez, K. D., \& Rogoff, B. (2003). Cultural ways of learning: Individual traits or repertoires of practice. Educational Researcher, 32(5), 19-25. http://doi.org/10.3102/0013189X032005019

Hall, S. (1996). Who Needs "Identity"? In P. du Gay \& S. Hall (Eds.), Questions of Cultural Identity (pp. 1-17). Thousands Oak, CA: SAGE Publications.

Heidegger, M. (1962). Being and Time. (J. Macquarrie \& E. Robinson, Trans.). New York, NY: Harper \& Row.

Hewitt, J. (2005). Toward an Understanding of How Threads Die in Asynchronous Computer Conferences. Journal of the Learning Sciences, 14(4), 567-589. http://doi.org/10.1207/s15327809j1s1404_4

Hine, C. (2000). Virtual Ethnography. Thousands Oak, CA: SAGE Publications.

Holland, D., Lachicotte Jr, W., Skinner, D., \& Cain, C. (1998). Identity and Agency in Cultural Worlds. Cambridge, MA: Harvard University Press.

Jenkins, R. (2008). Social Identity (3rd ed.). New York, NY: Taylor \& Francis.

Jordan, B., \& Henderson, A. (1995). Interaction Analysis: Foundations and Practice. Journal of the Learning Sciences, 4(1), 39-103. http://doi.org/10.1207/s15327809jls0401_2

Ke, F., Chávez, A. F., Causarano, P.-N. L., \& Causarano, A. (2011). Identity presence and knowledge building: Joint emergence in online learning environments? International Journal of Computer-Supported Collaborative Learning, 6(3), 349-370. http://doi.org/10.1007/s11412-011-9114-z

Kim, K.-J., \& Bonk, C. J. (2006). Cross-cultural Comparisons of Online Collaboration. Journal of ComputerMediated Communication, 8(1). http://doi.org/10.1111/j.1083-6101.2002.tb00163.x

Koschmann, T. (1996). Paradigm Shifts and Instructional Technology. In T. Koschmann (Ed.), CSCL: Theory and Practice of an Emerging Paradigm (pp. 1-23). Mahwah, NJ: Lawrence Erlbaum Associates.

Kuhn, T. S. (1970). The Structure of Scientific Revolutions (Enlarged, Second Edition). Chicago, IL: University of Chicago Press.

Ku, H.-Y., Pan, C.-C., Tsai, M.-H., Tao, Y., \& Cornell, R. A. (2004). The impact of instructional technology interventions on asian pedagogy. Educational Technology Research and Development, 52(1), 88-92.

Lave, J., \& Wenger, E. (1991). Situated Learning: Legitimate Peripheral Participation. New York, NY: Cambridge University Press.

Ligorio, M. B., Loperfido, F. F., \& Sansone, N. (2013). Dialogical positions as a method of understanding identity trajectories in a collaborative blended university course. International Journal of ComputerSupported Collaborative Learning, 8(3), 351-367. http://doi.org/10.1007/s11412-013-9174-3

Lyotard, J.-F. (1984). The Postmodern Condition: A Report on Knowledge. Minneapolis, MN: University Of 
Minnesota Press.

Maxwell, J. A. (2004). Qualitative Research Design: An Interactive Approach (2nd ed.). Thousands Oak, CA: SAGE Publications.

Merriam, S. B. (2009). Qualitative Research: A Guide to Design and Implementation (3rd ed.). San Francisco, CA: Jossey-Bass.

Mills, J., Eyre, G., \& Harvey, R. (2005). What makes provision of e-learning successful? Charles Sturt University's experience in Asia. Education for Information, 23(1), 43-55.

Nasir, N. S., \& Cooks, J. (2009). Becoming a Hurdler: How Learning Settings Afford Identities. Anthropology \& Education Quarterly, 40(1), 41-61. http://doi.org/10.1111/j.1548-1492.2009.01027.x

Nasir, N. S., Rosebery, A. S., Warren, B., \& Lee, C. D. (2005). Learning as a Cultural Process. In R. K. Sawyer \& R. K. Sawyer (Eds.), The Cambridge Handbook of the Learning Sciences (pp. 489-504). Cambridge, UK: Cambridge University Press.

Pea, R. D. (1993). Practices of distributed intelligence and designs for education. In G. Salomon (Ed.), Distributed Cognitions: Psychological and Educational Considerations (pp. 47-87). Cambridge, UK: Cambridge University Press.

Rovai, A. P., \& Ponton, M. K. (2005). An examination of sense of classroom community and learning among African American and Caucasian graduate students. Journal of Asynchronous Learning Networks, 9(3), 77-92.

Salomon, G. (Ed.). (1993). Distributed Cognitions: Psychological and Educational Considerations. Cambridge, UK: Cambridge University Press.

Saukko, P. (2005). Methodologies for Cultural Studies: An Integrative Approach. In N. K. Denzin \& Y. S. Lincoln (Eds.), The SAGE Handbook of Qualitative Research (3rd ed., pp. 343-356). Thousands Oak, CA: SAGE Publications.

Scardamalia, M. (2002). Collective cognitive responsibility for the advancement of knowledge. In B. Smith (Ed.), Liberal Education in a Knowledge Society (pp. 76-98). Chicago: Open Court.

Scardamalia, M., \& Bereiter, C. (1994). Computer Support for Knowledge-Building Communities. Journal of the Learning Sciences, 3(3), 265-283. http://doi.org/10.1207/s15327809j1s0303_3

Stahl, G. (2005). Group cognition in computer-assisted collaborative learning. Journal of Computer Assisted Learning, 21(2), 79-90.

Stahl, G. (2006). Group Cognition: Computer Support for Building Collaborative Knowledge. Cambridge, MA: The MIT Press.

Stahl, G., \& Hesse, F. (2009). Paradigms of shared knowledge. International Journal of Computer-Supported Collaborative Learning, 4(4), 365-369. http://doi.org/10.1007/s11412-009-9075-7

Sterne, J. (1999). Thinking the Internet: Cultural Studies Versus the Millennium. In S. Jones (Ed.), Doing Internet Research: Critical Issues and Methods for Examining the Net (pp. 257-288). Thousands Oak, CA: SAGE Publications.

Sullivan, P. (2001). Gender Differences and the Online Classroom: Male and Female College Students Evaluate Their Experiences. Community College Journal of Research and Practice, 25(10), 805-818.

Suthers, D. D. (2006). Technology affordances for intersubjective meaning making: A research agenda for CSCL. International Journal of Computer-Supported Collaborative Learning, 1(3), 315-337. http://doi.org/10.1007/s11412-006-9660-y

Tee, M., \& Karney, D. (2010). Sharing and cultivating tacit knowledge in an online learning environment. International Journal of Computer-Supported Collaborative Learning, 5(4), 385-413. http://doi.org/10.1007/s11412-010-9095-3

van Aalst, J. (2006). Rethinking the nature of online work in asynchronous learning networks. British Journal of Educational Technology, 37(2), 279-288. http://doi.org/10.1111/j.1467-8535.2006.00557.x

van Aalst, J. (2009). Distinguishing knowledge-sharing, knowledge-construction, and knowledge-creation discourses. International Journal of Computer-Supported Collaborative Learning, 4(3), 259-287. http://doi.org/10.1007/s11412-009-9069-5

Wenger, E. (1998). Communities of Practice: Learning, Meaning, and Identity. Cambridge, UK: Cambridge University Press.

Wise, A., \& Chiu, M. (2011). Analyzing temporal patterns of knowledge construction in a role-based online discussion. International Journal of Computer-Supported Collaborative Learning, 6(3), 445-470. http://doi.org/10.1007/s11412-011-9120-1

Zhang, J., Scardamalia, M., Reeve, R., \& Messina, R. (2009). Designs for Collective Cognitive Responsibility in Knowledge-Building Communities. Journal of the Learning Sciences, 18(1), 7-44. http://doi.org/10.1080/10508400802581676

Zingaro, D. (2012). Student Moderators in Asynchronous Online Discussion: a Question of Questions. Journal 